\title{
Gamma Vinyl-GABA Differentially Modulates NMDA Antagonist-Induced Increases in Mesocortical Versus Mesolimbic DA Transmission
}

Wynne K. Schiffer, B.S., Madina Gerasimov, D.D.S., Lauren Hofmann, B.S., Douglas Marsteller, B.S., Charles R. Ashby, Ph.D., Jonathan D. Brodie, M.D., Ph.D., David L. Alexoff, B.S., and Stephen L. Dewey, Ph.D.

To explore the role of endogenous GABA in NMDA antagonist induced dopamine (DA) release, we used in vivo microdialysis to study the effects of pretreatment with $\gamma$-vinyl GABA (GVG) on phencyclidine (PCP)-induced DA release in terminal regions of midbrain $D A$ neurons. GVG, an irreversible inhibitor of the GABA catabolizing enzyme $G A B A-A T$, significantly reduced the DA response to PCP $(7.0 \mathrm{mg} / \mathrm{kg})$ in freely moving animals. Preferential increases in PCP-induced DA release in the PFC (four-fold those of $N A c c)$ were dose-dependently inhibited by acute pretreatment with GVG at doses of 150 (51\% inhibition), $300(68 \%$ inhibition), and 500 (82\% inhibition) $\mathrm{mg} / \mathrm{kg}$, whereas NAcc PCP-induced DA activity was unresponsive to $150 \mathrm{mg} / \mathrm{kg}$ and only partially inhibited by 300 and 500 $m g / k g$. Subchronic treatment with GVG did not enhance the inhibitory capacity of the GABAergic system. While GVG evidently modulates PCP-induced increases in mesocorticolimbic DA transmission, the character of this modulation is regionally specific, with cortical NMDAantagonist induced increases appearing more sensitive to inhibition by endogenous GABA than subcortical areas. [Neuropsychopharmacology 25:704-712, 2001] (C) 2001 American College of Neuropsychopharmacology. Published by Elsevier Science Inc.
KEY WORDS: Phencyclidine; NMDA-antagonist; Microdialysis; Dopamine; Glutamate; GABA; Vigabatrin

N-methyl-D-aspartate (NMDA) glutamate-receptor antagonists like phencyclidine (PCP) and ketamine, traditionally considered substances of abuse, have more recently assumed a compelling role in exploratory para-

From the Chemistry Department, Brookhaven National Laboratory, Upton, NY (WKS, MG, LH, DM, CRA, DLA, SLD); and Department of Psychiatry, New York University School of Medicine, New York, NY (WKS, JDB, SLD).

Address correspondence to: Wynne K. Schiffer, Chemistry Department, Brookhaven National Laboratory, Upton, NY 11973.

Received 19 October 2000; revised 6 April 2001; accepted 13 April 2001.

Online publication: $4 / 16 / 01$ at www.acnp.org/citations/ Npp041601104. digms of schizophrenic psychoses (Javitt and Zukin 1991). In the past, conventional experimental models of schizophrenia focused on the effects of d-amphetamine, primarily because these and other psychostimulants directly increased dopamine (DA) release and induced a paranoid psychotic state in healthy controls similar to schizophrenia (Angrist and Gershon 1970; Wolkin et al. 1994). However, more recent models of schizophrenia focus on the effects of PCP and other NMDA antagonists, which produce psychoses that also incorporate the negative symptoms associated with schizophrenic illness (Javitt and Zukin 1991; Krystal et al. 1994). The psychotomimetic properties of NMDA antagonists provide a clinical foundation from which we can design novel treatment strategies targeted at diminishing aberrant neurochemical behavior. 
Investigations of the neurochemical interactions associated with NMDA antagonist-induced pathologies share the common denominator of increased subcortical DA concentrations and from this, many investigations have attempted to elucidate the events that produce abnormal DA activity. NMDA antagonists block excitatory amino acid (EAA) transmission at the NMDA receptor complex (Yamamoto et al. 1999). From this, many explanations suggest a hypo-glutamatergic state where diminished glutamatergic activity fails to activate the large number of inhibitory gamma aminobutyric acid (GABA) interneurons in the prefrontal cortex (PFC) (Yonezawa et al. 1998) or ventral tegmental area (VTA) (Bonci and Malenka 1999). This may produce dysfunctional cortical regulation of subcortical DA systems (Farber et al. 1998; Grace 1991). Indeed, local application of GABA receptor agonists dramatically reduces PCP-induced increases in PFC (Westerink et al. 1998; Yonezawa et al. 1998) and NAcc DA (Westerink et al. 1996; Wu et al. 1999).

On the other hand, a solid body of evidence indicates that a hyperactive glutamatergic state mediates increases in DA activity secondary to NMDA antagonist administration. Microdialysis studies have demonstrated concurrent increases in glutamatergic and dopaminergic activity in the PFC, Nacc, and VTA in response to an NMDA antagonist challenge (Moghaddam et al. 1997; Karreman et al. 1996; Svensson et al. 1997; Takahata and Moghaddam 1998). Unanticipated increases in glutamatergic activity in response to NMDA antagonism were attributed to increased synaptic availability of glutamate at non-NMDA alpha-amino-3hydroxy-5-metyloisoxazolo-4-propionate (AMPA)/kainate glutamate receptors.

Consistent with this hypothesis, systemic and local pretreatment with AMPA/kainate glutamate receptor antagonists reduced or completely blocked dopaminergic responsivity to PCP in the PFC (Moghaddam et al. 1997) and NAcc (Mathe et al. 1998), as well as locomotor effects produced by the highly selective NMDA antagonist, MK-801 (Hauber and Andersen 1993; Mathe et al. 1998; Moghaddam et al. 1997; Willins 1993). While these investigations suggest that EAA mediated processes represent the major mechanism by which NMDA antagonists increase mesocorticolimbic DA activity, the significant presence of cortical and subcortical GABAergic neurons (Mantz et al. 1992; Thierry et al. 1998; Bonci and Malenka 1999) poses an interesting therapeutic target.

Here we use microdialysis in freely moving animals to explore the effects of increased whole brain GABA levels on the mesocorticolimbic DA response to PCP. Gamma vinyl-GABA (GVG, vigabatrin) increases whole brain GABA levels through a receptor-independent mechanism that irreversibly blocks the enzyme responsible for GABA catabolism, GABA-aminotrans- ferase (GABA-AT) (Jung et al. 1977; Valdizan et al. 1999). This mode of action potentiates endogenously released GABA, which may be a favorable mechanism compared to the alternative approach of direct $\mathrm{GABA}_{\mathrm{A}}$ or $\mathrm{GABA}_{\mathrm{B}}$ agonists (Kalivas et al. 1990; Paladini and Tepper 1999; Westerink et al. 1996, 1998; Yang et al. 1999). Systemic administration of GVG inhibits the locomotor response to PCP (Seiler and Grauffel 1992) and diminishes the dopaminergic response to many psychoactive substances (Dewey et al. 1997; 1999; Gerasimov and Dewey 1999; Xi and Stein 2000). To our knowledge, this presents the first investigation of systemically increasing endogenous GABA levels in awake animals as an approach to mediate the neurochemical consequences of NMDA glutamate receptor antagonism.

\section{METHODS}

\section{Materials}

All animal use procedures were in strict accordance with the NIH Guide for the Care and Use of Laboratory Animals and were approved by the Institutional Animal Care and Use Committee. Adult male Sprague-Dawley rats were used in all experiments (200-300 g; Taconic Farms, Germantown, NY) and were given food and water ad libitum. Group size ranged from 6-8 animals. Temperature and humidity were kept relatively constant. Each animal was housed individually on a 12/12$\mathrm{h}$ light/dark cycle.

Rats were anesthetized with intraperitoneal (i.p.) chloral hydrate $(400 \mathrm{mg} / \mathrm{kg})$, and siliconized guide cannulae were implanted stereotaxically (PFC: anteriorposterior to bregma 3.7, medial-lateral to bregma -1.0 , dorsal-ventral to bregma -1.0; Nacc: anterior-posterior 1.5, medial-lateral -1.0, dorsal-ventral -5.6) (Paxinos and Watson 1982) two days prior to microdialysis. Dental acrylic and surgical screws were used to position the guide cannulae. On the day of the experiment, animals were removed from their home cage and placed in the dialysis chamber. Concentric flow dialysis probes (4 $\mathrm{mm}$ for PFC, $2 \mathrm{~mm}$ for NAcc) were placed into the guide cannulae in awake animals. The dialysis probes were perfused with artificial cerebrospinal fluid (aCSF: $155 \mathrm{mmol} \mathrm{NA}+, 1.1 \mathrm{mmol} \mathrm{Ca} 2+, 2.9 \mathrm{mmol} \mathrm{K}+, 132.76$ mmol Cl-, and $0.83 \mathrm{mmol} \mathrm{Mg2+)}$ using a microinfusion pump (BAS) at a flow rate of $2.0 \mu \mathrm{l} / \mathrm{min}$. After a 60min equilibration period, dialysate samples were collected every $20 \mathrm{~min}$ and injected on-line into the HPLC.

\section{Drug Treatment}

All drugs were dissolved in saline and administered by i.p. injection. In control studies, naïve rats were pretreated with vehicle (saline) 2.5 hours prior to a challenge with phencyclidine hydrochloride $(7.0 \mathrm{mg} / \mathrm{kg}$; 
Sigma Chemical Co., St. Louis, MO). With regard to the dose of PCP, we observed that $5.0 \mathrm{mg} / \mathrm{kg}$ had little effect on behavior or DA release, while $10 \mathrm{mg} / \mathrm{kg}$ produced behaviors that prevented the reproducible acquisition of extracellular DA activity. This also would have required immobilization of the animal, which might also have produced additional stress induced increases in DA transmission (Adams and Moghaddam 2000; Enrico et al. 1998; Kawahara et al. 1999). Treated animals were given either 150, 300, or $500 \mathrm{mg} / \mathrm{kg}$ GVG dissolved in $1 \mathrm{ml}$ saline solution $2.5 \mathrm{~h}$ prior to PCP challenge. Previously, we demonstrated that $2.5 \mathrm{~h}$ is an adequate period to allow GVG to maximally inhibit GABAT levels and subsequently provide maximal GABAergic inhibition of drug-induced DA transmission (Gerasimov et al. 2000).

Subchronic treatment studies involved 14 days of systemic GVG administration (i.p.) at doses of 150 and $300 \mathrm{mg} / \mathrm{kg}$. The control group received systemic saline for 14 days. Animals were not pretreated on the day of the experiment to differentiate the effects of acute from subchronic treatment, and instead received only an acute challenge dose of PCP $(7.0 \mathrm{mg} / \mathrm{kg})$.

\section{Biochemical Analysis, NAcc DA}

NAcc dialysate samples were assayed for DA content by high-pressure liquid chromatography (HPLC) coupled with electrochemical detection. The HPLC system consists of a BAS reverse-phase normbore column $(100 \times 3.2 \mathrm{~mm}, 3 \mu \mathrm{m} \mathrm{C18})$ and a BAS LC-4C electrochemical transducer with a dual glassy carbon electrode maintained at $+650 \mathrm{mV}$ relative to an $\mathrm{Ag} / \mathrm{AgCl}$ reference electrode. Data was collected on-line using ChromGraph $^{\circledR}$ software (BAS), as well as with a dualpen strip chart recorder. The mobile phase consisted of $7.0 \%$ methanol, $50 \mathrm{mmol}$ sodium phosphate monobasic, and $1.0 \mathrm{mmol}$ sodium octyl sulfate, and $0.1 \mathrm{mmol}$ EDTA, pH 4.0. Mobile phase was driven by a dual-pis-

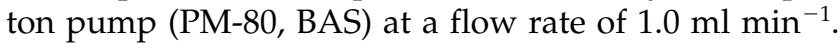
An online degasser was used to ensure that the mobile phase was free of air. Appropriate standards indicated dopamine elution occurred at $15 \mathrm{~min}$. Probe recovery was calculated as $13.8 \%$ from $2 \mathrm{~mm}$ NAcc probes with correction for tissue recovery over time.

\section{Biochemical Analysis, PFC DA}

PFC dialysate samples were assayed for DA content by microbore high-pressure liquid chromatography (HPLC) coupled with electrochemical detection. Relatively low basal levels of DA in the PFC required the increased sensitivity provided by microbore HPLC to assay dopamine concentrations in this region. Microbore HPLC has greater mass sensitivity, so a much smaller volume of sample can be injected on to the column in the same sampling period required for normbore. This HPLC system consists of a BAS reverse-phase microbore column $(150 \times 1 \mathrm{~mm}, 5 \mu \mathrm{m}$ microbore column with C18 packing; BAS, Bioanalytical Systems, Indiana) directly attached to a conventional flow electrochemical detector equipped with a glassy carbon working electrode maintained at $+650 \mathrm{mV}$ relative to a $\mathrm{Ag} / \mathrm{AgCl}$ reference electrode (LC-4C, BAS). The microbore column was kept at a constant temperature of $27.6^{\circ} \mathrm{C}$. The mobile phase consisted of $1 \mathrm{~L}\left(14.5 \mathrm{mM} \mathrm{NaH}{ }_{2} \mathrm{PO}_{4}\right.$, $30 \mathrm{mM}$ sodium citrate, $27 \mu \mathrm{m}$ disodium-EDTA, $10 \mathrm{mM}$ diethylamine $\mathrm{HCl}, 2.2 \mathrm{mM}$ 1-decanesulfonic acid, sodium salt), $\mathrm{pH}$ to 6.0 with $\mathrm{H}_{3} \mathrm{PO}_{4}, 80 \mathrm{ml}$ acetonitrile and $10 \mathrm{ml}$ tetrahydrofuran.

The net flow rate calibrated from the microbore column was $0.10 \mathrm{ml} \mathrm{min}^{-1}$, obtained by using a flow splitting technique in which a normbore $(100 \times 3.2 \mathrm{~mm}, 3$ $\mu \mathrm{m} \mathrm{C18)} \mathrm{column} \mathrm{(BAS)} \mathrm{was} \mathrm{used} \mathrm{in} \mathrm{parallel} \mathrm{to} \mathrm{the} \mathrm{mi-}$ crobore column as a dampening device via a three-way tee before the sample collecting loop. Data was collected on-line using ChromGraph ${ }^{\circledR}$ software (BAS) as well as with a dual-pen strip chart recorder. After all experiments, animals were euthanized with an overdose of chloral hydrate and brains dissected to verify probe placement.

\section{Quantitation Techniques}

Detection limits for normbore and microbore columns were $\sim 0.5 \mathrm{pg}$ and $0.1 \mathrm{fg}$, respectively, at a 2:1 signal to noise ratio. Standard curves ranging from to $10^{-15}$ to $10^{-6} \mathrm{~g} / \mathrm{ml}$ on the columns gave a linear increase in peak area (i.e., an $X$-fold increase in dopamine associated with an $X$-fold increase in peak area) with an $\mathrm{r}^{2}$ of 0.98 . NAcc DA measures in dialysate samples were far above the detection limits of normbore HPLC systems, with mean basal DA levels at $40 \pm 23 \mathrm{ng} / 5 \mu \mathrm{l}$. Microbore PFC DA measures in dialysate samples were low with readings in lower portions of daily standard curves. Estimated basal concentrations of PFC DA were $2.13 \pm 1.91 \mathrm{pg} / 5 \mu \mathrm{l}$

\section{Statistical Treatment}

For statistical and graphical analyses of the data from studies comparing the magnitude of dopaminergic response to PCP administration after subchronic or acute GVG pretreatment, data were analyzed and expressed as percentages of the three pre-drug baseline levels. Several factors prompted us to use percentage change values instead of absolute concentration measures for presentation of the current data sets. One, we needed to account for differences in technical attributes of microbore and normbore HPLC systems. Two, there appeared to be an inherent variability in absolute concentrations both across animals and across regions (PFC 
and NAcc), so percent change permitted more accurate comparisons of the relative magnitudes of each treatment effect. Where appropriate, we analyzed across treatment groups with a single-factor ANOVA. Post-hoc analysis was performed using Scheffe's test, which applies a critical value for the significance of the F statistic based on the number of comparisons, and is thus more stringent when comparing groups of equal and unequal size F (Munro 1997). Critical values for the F-statistic were evaluated at alpha $=0.05$. All statistical procedures were performed using Analyze-It Software ${ }^{\circledR}$ (Analyze-it Software, Ltd., Leeds, UK, WEB: http:// www.analyse-it.com) on a Windows based PC.

\section{RESULTS}

\section{Effects of PCP Alone on Basal Extracellular Levels of DA in PFC and NAcc}

Administration of PCP increased dialysate concentrations of DA preferentially in the PFC over NAcc (Figure 1). Specifically, PCP increased PFC DA $470 \pm 61.43 \%$ from baseline compared to an increase of $128 \pm 12.51 \%$ (significant difference between groups, $F(6,7)=21.025$, $p<.001)$ from baseline in the NAcc.

\section{Effects of GVG Pretreatment on PCP-Induced DA Activity in the PFC}

Acute pretreatment with GVG dose-dependently attenuated PCP-induced increases in cortical dialysate DA concentrations (Figure 2a). Figure 2a presents peak effects produced by PCP alone and in the presence of GVG, administered $2.5 \mathrm{~h}$ prior to the PCP challenge. At $150 \mathrm{mg} / \mathrm{kg}$, PCP increased DA $232 \pm 55.19 \%$, which indicates an attenuation of the DA response to PCP alone by $51 \%(\mathrm{t}=2.87 ; \mathrm{df}=6,5 ; p<.05)$. In animals treated with $300 \mathrm{mg} / \mathrm{kg} \mathrm{GVG}$, PCP increased extracellular DA $149 \pm 55.19 \%$ from baseline, inhibiting DA concentrations by $68 \%$ from controls $(t=5.08$; $\mathrm{df}=6,5 ; p<.01)$. Pretreatment with $500 \mathrm{mg} / \mathrm{kg}$ GVG produced PCPinduced increases in DA of $82 \pm 5.3 \%$, which represented an $86 \%$ attenuation from controls given PCP alone $(\mathrm{t}=6.27 ; \mathrm{df}=6,5 ; p<.001)$. A single factor ANOVA indicated a significant dose response across all doses tested: $\mathrm{F}(2,14)=4.38, p<.05$.

It appears that subchronic treatment with GVG attenuated PCP-induced increases in cortical dialysate DA concentrations; however, there was only a trend toward a dose-dependent relationship. Specifically, when PCP was given to animals subchronically pretreated with $300 \mathrm{mg} / \mathrm{kg}$ GVG, extracellular DA activity increased $246 \pm 19 \%$, while in animals pretreated with $150 \mathrm{mg} / \mathrm{kg}$ GVG, PCP-induced DA activity increased $313 \pm 38 \%$ (Figure $2 b$ ). In comparison to animals that received saline, subchronic treatment with $150 \mathrm{mg} / \mathrm{kg}$

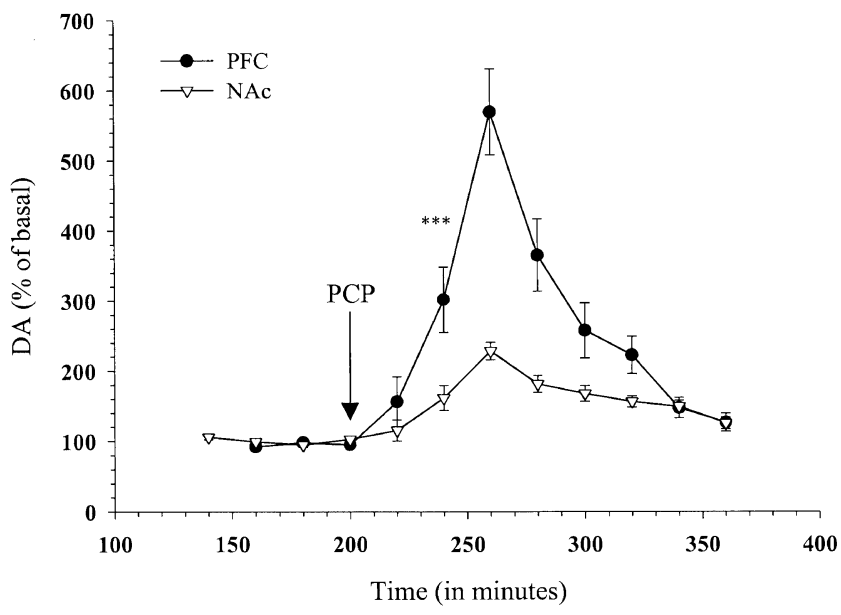

Figure 1. Effects of acute PCP administration $(7.0 \mathrm{mg} / \mathrm{kg})$ on extracellular DA in the prefrontal cortex (PFC) and nucleus accumbens (NAcc). Values represent percent change from baseline, with basal concentrations of PFC and NAcc DA estimated at 2 pg and 40 ng, respectively. Peak values in PFC are statistically different than peak values in NAcc $(* * *<.001 ; \mathrm{df} 6,7 ; \mathrm{F}=21.025$, single factor ANOVA).

GVG attenuated PCP-induced increases in DA by $55 \%$, while treatment with $300 \mathrm{mg} / \mathrm{kg}$ inhibited the DA response by $69 \%$. While peak values for subchronic treatment do not significantly differ from each other, they are significantly different from control $(p<.01$, df 2,13; $\mathrm{F}(2,14)=10.97)$. With regard to a comparison to the 51 and $68 \%$ inhibition produced by acute GVG administration (150 vs. $300 \mathrm{mg} / \mathrm{kg}$, respectively) (Figure 2a), it is clear that subchronic administration did not potentiate the inhibition of DA responsivity to a PCP challenge.

\section{Effects of GVG Pretreatment on PCP-Induced DA Activity in the NAcc}

Acute pretreatment with GVG inhibited PCP-induced increases in subcortical dialysate DA levels when given at higher doses (Figure 3a). When administered $2.5 \mathrm{~h}$ prior to PCP $(7.0 \mathrm{mg} / \mathrm{kg})$, a dose of $150 \mathrm{mg} / \mathrm{kg}$ GVG did not significantly attenuate subcortical DA responsivity. However, pretreatment doses of 300 and 500 $\mathrm{mg} / \mathrm{kg}$ produced 26 and $23 \%$ attenuation, respectively $(\mathrm{F}(2,21)=14.62, p<.001)$. These values were calculated from the three values immediately prior to PCP administration, to normalize the magnitude of the acute response with the subchronic response and compensate for possible prelowering of DA levels across all treatment groups.

Subchronic administration of GVG did not inhibit subcortical PCP-induced DA responsivity (Figure 3b). Following $150 \mathrm{mg} / \mathrm{kg}$ GVG pretreatment once daily for 14 days, the response to PCP was inhibited from controls pretreated with saline by $13 \%$. In animals treated subchronically with $300 \mathrm{mg} / \mathrm{kg}$ GVG, PCP produced a 
a.

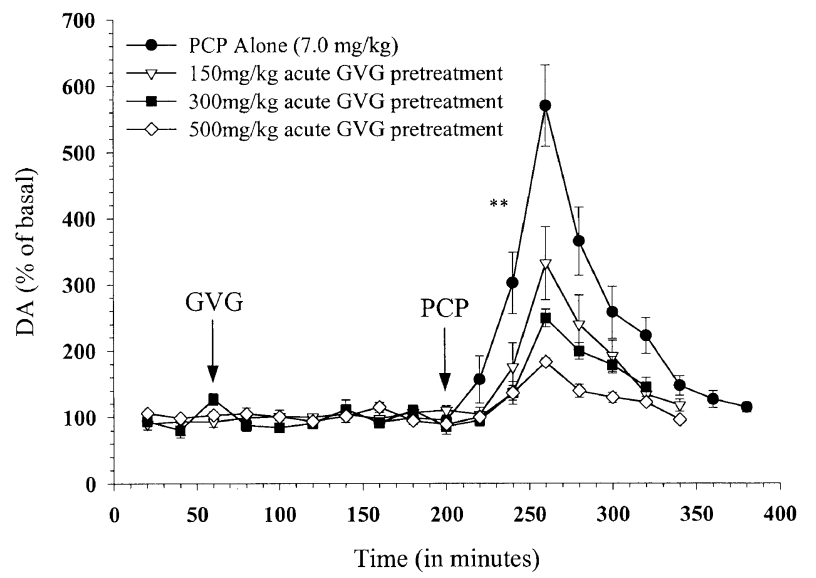

b.

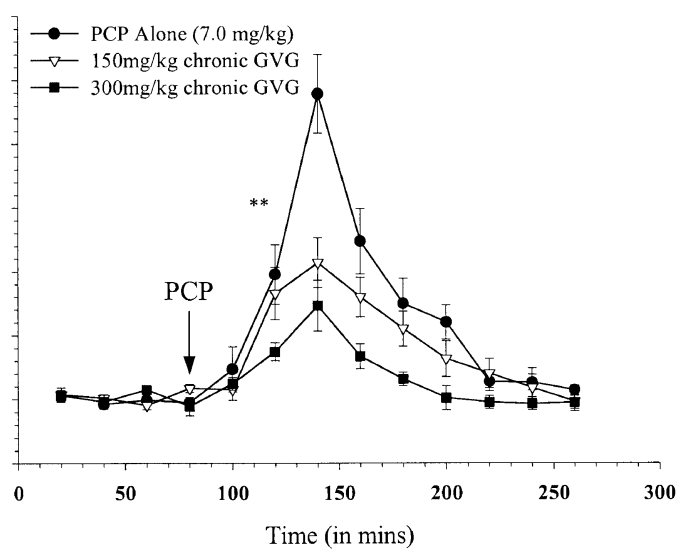

Figure 2. Effects of acute (a) or subchronic (b) GVG on PFC DA responsivity to a PCP challenge. Peak values for (a) are statistically different from each other $(p<.05 ; \mathrm{df} 2,14 ; \mathrm{F}=4.38$, single factor ANOVA across dose range), and from control values $\left({ }^{*} p<.05, \mathrm{t}=2.87,{ }^{* *} p<.01, \mathrm{t}=5.08,{ }^{* * * *} p<.001, \mathrm{t}=6.27\right)$. Peak values for subchronic (b) $150 \mathrm{mg} / \mathrm{kg}$ and $300 \mathrm{mg} / \mathrm{kg}$ do not differ from each other, but are significantly different from control $(* * p<.01, \mathrm{df} 2,13 ; \mathrm{F}=10.97)$. Subsubchronic treatment with GVG did not significantly alter basal levels of PFC DA, with mean \pm standard deviation values for saline and GVG treated animals at $2.13 \pm 1.91$ and $1.41 \pm 2.058 \mathrm{pg} / 5 \mu \mathrm{l}(\mathrm{t}=1.259, p=.214)$.

$212 \pm 17 \%$ increase in basal DA concentrations, while PCP in animals treated with the lower dose of GVG produced similar increases $(211 \pm 26 \%)$. Neither of these subchronic treatment regimens differed significantly from the control group ( $12 \%$ inhibition), indicating a lack of effect on PCP-induced increases in extracellular DA levels.

A separate group of animals underwent a dual-insertion paradigm where basal levels of DA and DOPAC were assessed prior to a two-week treatment regimen with saline or GVG at 150 and $300 \mathrm{mg} / \mathrm{kg}$, when probes were re-inserted and basal levels were again assessed. Consistent with other dual-insertion microdialysis studies (Georgieva et al. 1993), DOPAC levels decreased in animals that received GVG treatment, but in all groups the response to a PCP challenge $(7.0 \mathrm{mg} / \mathrm{kg})$ was significantly diminished, consistent with findings from Camp and Robinson (1992). Due to considerable differences between the DA response to a PCP challenge in animals where probes were inserted twice and in animals where probes were inserted only on the day of the challenge, data from animals that underwent the dual-insertion procedure is not presented. Further, according to our standard curve analysis there was no significant difference in basal DA in animals that re- a.

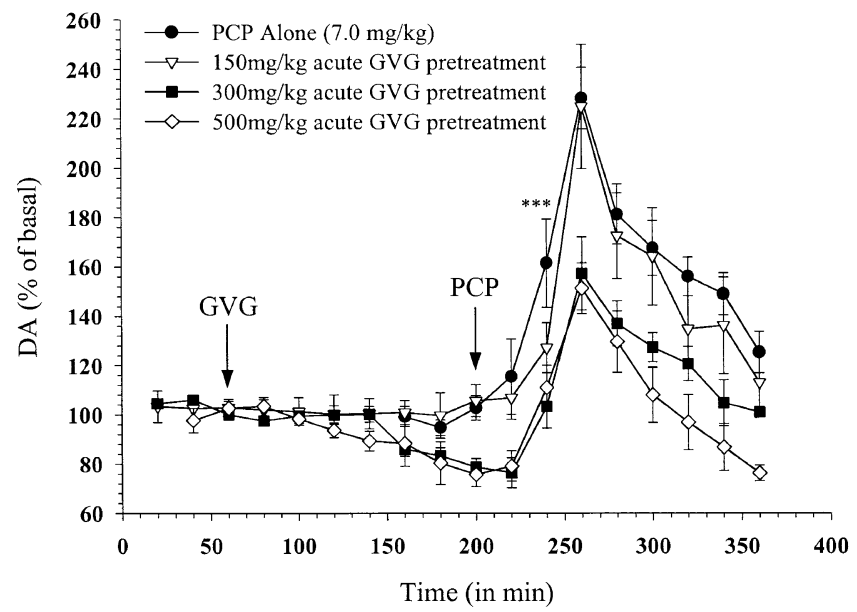

b.

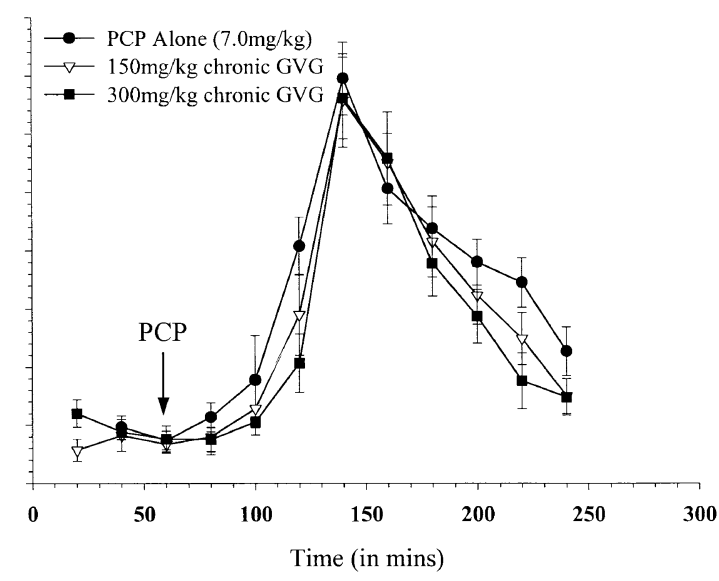

Figure 3. Effects of acute (a) or subchronic (b) GVG on NAcc DA responsivity to a PCP challenge. Peak values following GVG at 300 and $500 \mathrm{mg} / \mathrm{kg}$ are significantly different from control ${ }^{* * *} p<.001 ; \mathrm{df} 2,21 ; \mathrm{F}=14.62$ single factor ANOVA). Subsubchronic treatment with GVG did not significantly alter basal levels of NAcc DA, with mean values for saline and GVG treated animals at $40 \pm 23$ and $29 \pm 21 \mathrm{ng} / 5 \mu \mathrm{l}$ respectively $(\mathrm{t}=1.550, p=.127)$. 
ceived saline or subchronic GVG treatment, although this could be attributed to the inherent variability of basal differences expressed by these animals, as animals treated with GVG expressed lower concentrations but the difference was not significant due to variability within treatment groups.

\section{DISCUSSION}

This investigation demonstrates a potentially significant inhibitory role of the GABAergic system in the glutamatergic modulation of mesocorticolimbic dopamine activity, and helps clarify some unresolved interactions within the mesocorticolimbic neurotransmitter system. In both the PFC and NAcc, increased whole brain GABA levels significantly attenuated PCPinduced DA release. The character of this inhibition reflects inherent differences between mesocortical and mesolimbic systems, where lower doses of GVG significantly inhibit PFC DA (Figure 2a) and do not affect subcortical DA (Figure 3a). Further, the inhibitory potential of GVG was not enhanced by subchronic pretreatment in either region (Figures $2 \mathrm{~b}$ and $3 \mathrm{~b}$ ). Here, we demonstrate an interesting discrepancy in the regulatory properties of cortical and subcortical interactions unique to NMDA antagonism and with possible relevance to schizophrenic psychoses (Weinberger et al. 1994), where a likely explanation lies in physiologically and functionally distinct excitation of inhibitory processes within the mesocorticolimbic system.

Cortical increases in PCP induced DA release, which were four-fold those of subcortical increases, were more responsive to GABAergic modulation. Specifically, our data indicate lower doses of GVG $(150 \mathrm{mg} / \mathrm{kg})$ significantly attenuated PCP induced DA release in the PFC but failed to modulate PCP induced NAcc DA release. Consistent with this observation, acute GVG pretreatment with doses lower than $200 \mathrm{mg} / \mathrm{kg}$ did not significantly reduce the locomotor response to PCP administration (Seiler and Grauffel 1992), where locomotion represents an index of neural activity in subcortical structures (French et al. 1985; Steinpreis and Salamone 1993). Further, subchronic pretreatment with GVG, demonstrated in other studies to enhance GABAergic inhibition of NAcc DA in response to cocaine (Morgan and Dewey 1998), had no effect on PCP induced NAcc DA transmission but significantly inhibited PCP induced PFC DA activity. This data supports a significant body of evidence indicating that glutamatergic modulation of dopamine release at the cell body (VTA) and the nerve terminal level (PFC and NAcc) is different for mesocortical vs. mesolimbic DA neurons. Furthermore, these findings are consistent with the notion that NMDA antagonists may exert their modulatory effects cortically, by direct excitation and subcortically, through disinhibition.

Neuroanatomical evidence supports a system comprised of discrete populations of mesocortical and mesolimbic DA and GABA projection neurons differentially influenced by excitatory cortical afferents (Carr and Sesack 1998, 2000a; Tong et al. 1998). Specifically, excitatory PFC efferents synapse on mesocortical DA and mesolimbic GABA neurons, but not mesocortical GABA (Carr and Sesack 2000b; Lokwan et al. 2000; Takahata and Moghaddam 2000) or mesolimbic DA neurons (Carr and Sesack 2000b). Mesocortical DA and GABA neurons are also equally subject to excitatory regulation by NMDA and non-NMDA AMPA receptors (Bonci and Malenka 1999; Takahata and Moghaddam 1998), and it has been proposed that NMDA antagonists increase glutamatergic availability at nonNMDA glutamate receptors (Bubser et al. 1992; Mathe et al. 1998; Moghaddam et al. 1997; Moghaddam and Adams 1998; Svensson et al. 1997). In the present study, cortical increases in PCP-induced DA release appear more sensitive to modulation by endogenous GABA than subcortical areas, supporting evidence that the GABA component of the mesocortical pathway is spared from NMDA receptor antagonism.

Lower doses of GVG failed to inhibit PCP-induced increases in NAcc DA. These findings support the contention that blockade of NMDA receptors diminishes the activity of mesolimbic GABA neurons (Carr and Sesack 2000b). Thus, increasing presynaptic GABA levels should have little influence in the presence of diminished afferent stimulation. Both high GVG doses produced a similar degree of inhibition consistent with an apparent ceiling effect of mesolimbic GABAergic inhibition. While the properties of irreversible enzyme inhibition make it unlikely, it is conceivable that tolerance to GVG develops over time. Although not directly assessed, previous studies with GVG demonstrate dosedependent elevations in brain GABA concentrations produced by the same doses used in the present study (Arteaga et al. 1992; Qume and Fowler 1997; Valdizan and Armijo 1992). Specific to the NAcc, significant reciprocal connections with the VTA utilize GABA as the main neurotransmitter (Nauta et al. 1978; Waddington and Cross 1978; Wallas and Fonnum 1980), forming a closed neuronal loop with mesolimbic DA neurons which appears to be influenced by a large number of local GABAergic interneurons (Bayer and Pickel 1991; Bolam et al. 1983).

It has been proposed that GABA receptors may be simultaneously located on both dopaminergic projection neurons and GABAergic interneurons, with the net effect of GABA on DA cell function dependent on a functional balance of both direct inhibition and indirect disinhibition ( $\mathrm{Xi}$ and Stein 1998). Given that mesolimbic GABA projection neurons are inhibited by glutamater- 
gic antagonism (Carr and Sesack 2000b), it is possible that a threshold exists whereby local GABAergic interneurons can exert an inhibitory effect on mesolimbic DA neurons only in the presence of significantly increased concentrations of vesicular pools of GABA associated with higher doses of GVG (Arteaga et al. 1992; Qume and Fowler 1997; Valdizan and Armijo 1992). Alternatively, it could be speculated that diminished input to mesolimbic GABA projection neurons does not completely inactivate their ability to function, but diminishes their activity such that when they are stimulated, an increased inhibitory potential from larger presynaptic pools enables an overall inhibition in spite of diminished neuronal stimulation.

Here, we demonstrate NMDA-antagonist induced DA release in the PFC is susceptible to increases in endogenous GABA levels. If cortical PCP-induced increases in extracellular DA were the product of diminished mesocortical DA stimulation of local GABA interneurons (Yonezawa et al. 1998), the sensitivity of cortical DA to increases in endogenous GABA would more likely reflect what we see in the NAcc, where there is a degree of insensitivity at lower doses of GVG. This is also supported by data in the present study indicating subchronic treatment with GVG inhibited cortical, but not subcortical, PCP-induced increases in DA. It has been demonstrated that subchronic treatment with GVG at doses similar to those employed in the present study progressively increase presynaptic GABA pools (Qume and Fowler 1997). This is consistent with our previous findings of enhanced inhibition of cocaineinduced increases in extracellular DA with a longer pretreatment duration (Morgan and Dewey 1998). That subchronic GVG enhances the inhibition of cocaine, but not PCP-induced increases in NAcc DA, contributes to theories regarding the selective nature of glutamateinduced DA release. This data is consistent with an apparent sparing of healthy cortical GABAergic function in the presence of NMDA antagonists, but pronounced disturbances in normal GABAergic inhibition of subcortical DA activity.

GVG presents a non-receptor mediated approach for increasing whole brain GABA levels, which subsequently increases GABAergic inhibition in different brain regions without the regional preference exhibited by specific receptor agonists (Kalivas et al. 1990; Paladini and Tepper 1999; Westerink et al. 1996, 1998; Yang et al. 1999). Preemptive restoration of inhibitory function in cortical and subcortical areas may provide a mechanism to control aberrant neuronal activity. Specific to NMDA-antagonist induced increases in DA responsivity, whether the product of a hyper- or hypo glutamatergic state, increased endogenous GABA levels appear to modulate DA activity secondary to altered glutamatergic transmission.

Many investigations have suggested dysfunctional
GABAergic modulation in schizophrenia (Dean et al. 1999 or for review see Keverne 1999), although pharmacotherapy with current GABAergic agents has been limited by the high abuse liability of these compounds (Koob 1998), and the increased susceptibility to addiction found in schizophrenic patients (Cuffel et al. 1993; DeQuardo et al. 1994). Our findings (Dewey et al. 1998), combined with data from Takada and coworkers (Takada and Yanagita 1997) demonstrate that, unlike many receptor-mediated GABA agonists, GVG itself is not addictive. Ongoing studies will address the utility of increasing inhibitory GABAergic activity with GVG as a possible adjunct to neuroleptic therapy in a subpopulation of schizophrenic patients, as well as further elucidating the mechanisms of GABAergic control over related neurotransmitter systems in the living brain.

\section{ACKNOWLEDGMENTS}

This research was carried out at Brookhaven National Laboratory under contract with the U.S. Department of Energy Office of Biological and Environmental Research (USDOE/OBER DE-AC02-98CH10886), the National Institutes of Mental Health (NIMH MH49165 and NIMH R2955155), and the National Institute on Drug Abuse (5RO-DA06278). Partial funding provided by Eli Lilly Pharmaceuticals, Inc.

\section{REFERENCES}

Adams BW, Moghaddam B (2000): Tactile stimulation activates dopamine release in the lateral septum. Brain Res 858:177-180

Angrist BM, Gershon S (1970): The phenomenology of experimentally induced amphetamine psychosis - preliminary observations. Biol Psychiatry 2:95-107

Arteaga R, Herranz JL, Valdizan EM, Armijo JA (1992): Gamma-vinyl GABA (vigabatrin): Relationship between dosage, plasma concentrations, platelet GABA-transaminase inhibition, and seizure reduction in epileptic children. Epilepsia 33:923-931

Bayer VE, Pickel VM (1991): GABA-labeled terminals form proportionally more synapses with dopaminergic neurons containing low densities of tyrosine hydroxylaseimmunoreactivity in rat ventral tegmental area. Brain Res 559:44-55

Bolam JP, Clark DJ, Smith AD, Somogyi PA (1983): A type of aspiny neuron in the rat neostriatum accumulates $3 \mathrm{H}$ gamma-hydroxybutyric acid: Combination of Golgistaining, autoradiography, and electron microscopy. J Comp Neurol 213:121-134

Bonci A, Malenka RC (1999): Properties and plasticity of excitatory synapses on dopaminergic and GABAergic cells in the ventral tegmental area. J Neurosci 19:3723-3730

Bubser M, Keseberg U, Notz PK, Schmidt WJ (1992): Differential behavioural and neurochemical effects of competitive and non-competitive NMDA receptor antagonists in rats. Eur J Pharmacol 229:75-82 
Camp DM, Robinson TE (1992): On the use of multiple probe insertions at the same site for repeated intracerebral microdialysis experiments in the nigrostriatal dopamine system of rats. J Neurochem 58:1706-1715

Carr DB, Sesack S (2000a): GABA-containing neurons in the rat ventral tegmental area project to the prefrontal cortex. Synapse 38:114-123

Carr DB, Sesack SR (1998): Callosal terminals in the rat prefrontal cortex: Synaptic targets and association with GABA-immunoreactive structures. Synapse 29:193-205

Carr DB, Sesack SR (2000b): Projections from the rat prefrontal cortex to the ventral tegmental area: Target specificity in the synaptic associations with mesoaccumbens and mesocortical neurons. J Neurosci 20:3864-3873

Cuffel BJ, Heithoff KA, Lawson W (1993): Correlates of patterns of substance abuse among patients with schizophrenia. Hosp Commun Psychiatry 44:247-251

Dean B, Hussain T, Hayes W, Scarr E, Kitsoulis S, Hill C, Opeskin K, Copolov DL (1999): Changes in serotonin2A and $\mathrm{GABA}(\mathrm{A})$ receptors in schizophrenia: Studies on the human dorsolateral prefrontal cortex. J Neurochem 72:1593-1599

DeQuardo JR, Carpenter CF, Tandon R (1994): Patterns of substance abuse in schizophrenia: Nature and significance. J Psychiatr Res 28:267-275

Dewey SL, Brodie JD, Gerasimov M, Horan B, Gardner EL, Ashby CRJ (1999): A pharmacologic strategy for the treatment of nicotine addiction. Synapse 31:76-86

Dewey SL, Chaurasia CS, Chen CE, Volkow ND, Clarkson FA, Porter SP, Straughter-Moore RM, Alexoff DL, Tedeschi D, Russo NB, Fowler JS, Brodie JD (1997): GABAergic attenuation of cocaine-induced dopamine release and locomotor activity. Synapse 25:393-398

Dewey SL, Morgan AE, Ashby CR Jr, Horan B, Kushner SA, Logan J, Volkow ND, Fowler JS, Gardner EL, Brodie JD (1998): A novel strategy for the treatment of cocaine addiction. Synapse 30:119-129

Enrico P, Bouma M, de Vries JB, Westerink BH (1998): The role of afferents to the ventral tegmental area in the handling stress-induced increase in the release of dopamine in the medial prefrontal cortex: A dual-probe microdialysis study in the rat brain. Brain Res 779:205-213

Farber NB, Newcomer JW, Olney JW (1998): The glutamate synapse in neuropsychiatric disorders. Focus on schizophrenia and Alzheimer's disease. Prog Brain Res 116:421-437

French ED, Pilapil C, Quirion R (1985): Phencyclidine binding sites in the nucleus accumbens and phencyclidineinduced hyperactivity are decreased following lesions of the mesolimbic dopamine system. Eur J Pharmacol $116: 1-9$

Georgieva J, Luthman J, Mohringe B, Magnusson O (1993): Tissue and microdialysate changes after repeated and permanent probe implantation in the striatum of freely moving rats. Brain Res Bull 31:463-470

Gerasimov MR, Dewey SL (1999): Gamma-vinyl gammaaminobutyric acid attenuates the synergistic elevations of nucleus accumbens dopamine produced by a cocaine/ heroin (speedball) challenge. Eur J Pharmacol 380:1-4

Gerasimov MR, Schiffer WK, Brodie JD, Lennon IC, Taylor
SJC, Dewey SL (2000): gamma-Aminobutyric acid mimetic drugs differentially inhibit the dopaminergic response to cocaine. Eur J Pharmacol 395:129-135

Grace AA (1991): Phasic versus tonic dopamine release and the modulation of dopamine system responsivity: A hypothesis for the etiology of schizophrenia. Neuroscience 41:1-24

Hauber W, Andersen R (1993): The non-NMDA glutamate receptor antagonist GYKI 52466 counteracts locomotor stimulation and anticataleptic activity induced by the NMDA antagonist dizocilpine. Naunyn Schmiedebergs Arch Pharmacol 348:486-490

Javitt DC, Zukin SR (1991): Recent advances in the phencyclidine model of schizophrenia. Am J Psychiatry 148: 1301-1308

Jung MJ, Lippert B, Metcalf BW, Bohlen P, Schechter PJ (1977): Gamma-Vinyl GABA (4-amino-hex-5-enoic acid), a new selective irreversible inhibitor of GABA-T: effects on brain GABA metabolism in mice. J Neurochem 29:797-802

Kalivas PW, Duffy P, Eberhardt H (1990): Modulation of A10 dopamine neurons by gamma-aminobutyric acid agonists. J Pharmacol Exp Ther 253:858-866

Karreman M, Westerink BH, Moghaddam B (1996): Excitatory amino acid receptors in the ventral tegmental area regulate dopamine release in the ventral striatum. J Neurochem 67:601-607

Kawahara Y, Kawahara H, Westerink BH (1999): Comparison of effects of hypotension and handling stress on the release of noradrenaline and dopamine in the locus coeruleus and medial prefrontal cortex of the rat. Naunyn Schmiedebergs Arch Pharmacol 360:42-49

Keverne EB (1999): GABA-ergic neurons and the neurobiology of schizophrenia and other psychoses. Brain Res Bull 48:467-473

Koob GF (1998): Circuits, drugs, and drug addiction. Adv Pharmacol 42:978-982

Krystal JH, Karper LP, Seibyl JP, Freeman GK, Delaney R, Bremner JD, Heninger GR, Bowers MB Jr, Charney DS (1994): Subanesthetic effects of the noncompetitive NMDA antagonist, ketamine, in humans. Psychotomimetic, perceptual, cognitive, and neuroendocrine responses. Arch Gen Psychiatry 51:199-214

Lokwan SJ, Overton PG, Berry MS, Clark D (2000): The medial prefrontal cortex plays an important role in the excitation of A10 dopaminergic neurons following intravenous muscimol administration. Neuroscience 95:647-656

Mantz J, Godbout R, Pirot S, Glowinski J, Thierry AM (1992): Inhibitory effects of mesocortical dopaminergic neurons on their target cells: Electrophysiological and pharmacological characterization. Neurochem Int 20(Suppl): 251S-254S

Mathe JM, Nomikos GG, Schilstrom B, Svensson TH (1998): Non-NMDA excitatory amino acid receptors in the ventral tegmental area mediate systemic dizocilpine (MK801 ) induced hyperlocomotion and dopamine release in the nucleus accumbens. J Neurosci Res 51:583-592

Moghaddam B, Adams B, Verma A, Daly D (1997): Activation of glutamatergic neurotransmission by ketamine: A novel step in the pathway from NMDA receptor block- 
ade to dopaminergic and cognitive disruptions associated with the prefrontal cortex. J Neurosci 17:2921-2927

Moghaddam B, Adams BW (1998): Reversal of phencyclidine effects by a group II metabotropic glutamate receptor agonist in rats. Science 281:1349-1352

Morgan AE, Dewey SL (1998): Effects of pharmacologic increases in brain GABA levels on cocaine-induced changes in extracellular dopamine. Synapse 28:60-65

Munro BH (1997): Statistical Methods for Health Care Research, 3rd ed. New York, NY, Lippincott

Nauta WHH, Smith GP, Faull RLM, Domesick VB (1978): Efferent connections and nigral afferents of the nucleus accumbens septi in the rat. Neuroscience 3:91-102

Paladini CA, Tepper JM (1999): GABA(A) and GABA(B) antagonists differentially affect the firing pattern of substantia nigra dopaminergic neurons in vivo. Synapse 32:165-176

Paxinos G, Watson C (1982): The rat brain in stereotaxic coordinates. Sydney, Academic Press.

Qume M, Fowler LJ (1997): Effect of chronic treatment with the GABA transaminase inhibitors gamma-vinyl GABA and ethanolamine O-sulphate on the in vitro GABA release from rat hippocampus. Br J Pharmacol 122:539-545

Seiler N, Grauffel C (1992): Antagonism of phencyclidineinduced hyperactivity in mice by elevated brain GABA concentrations. Pharmacol Biochem Behav 41:603-606

Steinpreis RE, Salamone JD (1993): The role of nucleus accumbens dopamine in the neurochemical and behavioral effects of phencyclidine: A microdialysis and behavioral study. Brain Res 612:263-270

Svensson TH, Mathe JM, Nomikos GG, Schilstrom B, Marcus M, Fagerquist M (1997): Interactions between catecholamines and serotonin: Relevance to the pharmacology of schizophrenia. In Goldstein DS, Eisenhofer G, McCarty R (eds), Advances in Pharmacology. New York, NY, Academic Press, pp 814-818

Takada K, Yanagita T (1997): Drug dependence study on vigabatrin in rhesus monkeys and rats. Arzneimittelforschung 47:1087-1092

Takahata R, Moghaddam B (1998): Glutamatergic regulation of basal and stimulus-activated dopamine release in the prefrontal cortex. J Neurochem 71:1443-1449

Takahata R, Moghaddam B (2000): Target-specific glutamatergic regulation of dopamine neurons in the ventral tegmental area. J Neurochem 75:1775-1778

Thierry AM, Pirot S, Gioanni Y, Glowinski J (1998): Dopamine function in the prefrontal cortex. Adv Pharmacol 42:717-720

Tong ZY, Overton PG, Martinez-Cue C, Clark D (1998): Do non-dopaminergic neurons in the ventral tegmental area play a role in the responses elicited in A10 dopaminergic neurons by electrical stimulation of the prefrontal cortex? Exp Brain Res 118:466-476

Valdizan EM, Armijo JA (1992): Effects of single and multiple increasing doses of vigabatrin on brain GABA metabolism and correlation with vigabatrin plasma concentration. Biochem Pharmacol 43:2143-2150
Valdizan EM, Garcia AP, Armijo JA (1999): Effects of increasing doses of vigabatrin on platelet gamma-aminobutyric acid-transaminase and brain gamma-aminobutyric acid in rats. Eur J Pharmacol 369:169-173

Waddington JL, Cross AJ (1978): Neurochemical changes following kainic acid lesions of the nucleus accumbens: Implication for a GABAergic accumbotegmental pathway. Life Sci 22:1011-1014

Wallas I, Fonnum F (1980): Biochemical evidence for gamma-aminobutyrate-containing fibers from the nucleus accumbens to the substantia nigra and ventral tegmental area in the rat. Neuroscience 5:63-72

Weinberger DR, Aloia MS, Goldberg TE, Berman KF (1994): The frontal lobes and schizophrenia. J Neuropsychiatry Clin Neurosci 6:419-427

Westerink BH, Enrico P, Feimann J, de Vries JB (1998): The pharmacology of mesocortical dopamine neurons: A dual-probe microdialysis study in the ventral tegmental area and prefrontal cortex of the rat brain. J Pharmacol Exp Ther 285:143-154

Westerink BH, Kwint HF, de Vries JB (1996): The pharmacology of mesolimbic dopamine neurons: A dual-probe microdialysis study in the ventral tegmental area and nucleus accumbens of the rat brain. J Neurosci 16:26052611

Willins D (1993): The role of dopamine and AMPA/kainate receptors in the nucleus accumbens in the hypermotility response to MK-801. Pharmacol Biochem Behav 46:881-887

Wolkin A, Sanfilipo M, Angrist B, Duncan E, Wieland S, Wolf AP, Brodie JD, Cooper TB, Laska E, Rotrosen JP (1994): Acute d-amphetamine challenge in schizophrenia: Effects on cerebral glucose utilization and clinical symptomatology. Biol Psychiatry 36:317-325

Wu YN, Shen KZ, Johnson SW (1999): Presynaptic inhibition preferentially reduces in NMDA receptor-mediated component of transmission in rat midbrain dopamine neurons. Br J Pharmacol 127:1422-1430

Xi ZX, Stein EA (1998): Nucleus accumbens dopamine release modulation by mesolimbic GABA(A) receptors - an in vivo electrochemical study. Brain Res 798:156-165

Xi ZX, Stein EA (2000): Increased mesolimbic GABA concentration blocks heroin self-administration in the rat. J Pharmacol Exp Ther 294:613-619

Yamamoto Y, Kakigi T, Maeda K (1999): Intra-striatal phencyclidine inhibits N-methyl-D-aspartic acid-stimulated increase in glutamate levels of freely moving rats. Prog Neuropsychopharmacol Biol Psychiatry 23:161-174

Yang CR, Seamans JK, Gorelova N (1999): Developing a neuronal model for the pathophysiology of schizophrenia based on the nature of electrophysiological actions of dopamine in the prefrontal cortex. Neuropsychopharmacology 21:161-194

Yonezawa Y, Kuroki T, Kawahara T, Tashiro N, Uchimura H (1998): Involvement of gamma-aminobutyric acid neurotransmission in phencyclidine-induced dopamine release in the medial prefrontal cortex. Eur J Pharmacol 341:45-56 